International Journal of Biological Macromolecules

Volume 137, 15 September 2019, Pages 197-204

https://doi.org/10.1016/j.ijbiomac.2019.06.204

\title{
Poly(lactic acid)/cellulose nanocrystal composites via the Pickering emulsion approach: rheological, thermal and mechanical properties
}

\author{
Yunchong Zhang ${ }^{\mathrm{a}}$, Lu Cui ${ }^{\mathrm{b}, \mathrm{c}}$, Hong Xu ${ }^{\mathrm{a}}$, Xueling Feng ${ }^{\mathrm{a}}$, Bijia Wanga ${ }^{\mathrm{a}}$, Béla \\ Pukánszky b,c,*, Zhiping Mao ${ }^{\mathrm{a}}$, Xiaofeng Sui ${ }^{\mathrm{a}, *}$
}

${ }^{a}$ Key Lab of Science and Technology of Eco-Textile, Ministry of Education, College of Chemistry, Chemical Engineering and Biotechnology, Donghua University, Shanghai 201620, People's Republic of China

${ }^{\mathrm{b}}$ Institute of Materials and Environmental Chemistry, Research Centre for Natural Sciences, Hungarian Academy of Sciences, H-1519 Budapest, P.O. Box 286, Hungary

${ }^{\mathrm{c}}$ Laboratory of Plastics and Rubber Technology, Department of Physical Chemistry and Materials Science, Budapest University of Technology and Economics, H-1521 Budapest, P.O. Box 91, Hungary

*Corresponding author: E-mail: suixf@dhu.edu.cn, E-mail: BPukanszky@mail.bme.hu 


\begin{abstract}
Cellulose nanocrystals (CNCs) were evenly dispersed into poly(lactic acid) (PLA) via the Pickering emulsion approach. The PLA/CNC composites prepared were studied by rheological, thermal as well as mechanical measurements. Changes in the rheological characteristics of the composites showed that $\mathrm{CNC}$ promoted the transition of the composites from fluid to solid-like behavior at high temperatures. The introduction of $5 \mathrm{wt} \% \mathrm{CNC}$ improved the crystallinity of PLA considerably and increased the onset temperature of crystallization by about $10{ }^{\circ} \mathrm{C}$. The storage modulus of the composites increased throughout the entire temperature range of testing. Flexural modulus was improved considerably. All the results indicated that the Pickering emulsion approach improves the dispersion of CNC in the PLA matrix and CNC improves efficiently most properties of PLA.
\end{abstract}

Keywords: Dispersion, Reinforcement, Network formation, Crystallinity, Molecular mobility 


\section{Introduction}

Poly(lactic acid) (PLA) is a biodegradable thermoplastic polyester derived from renewable resources such as corn, wheat or potato. PLA has been extensively studied over the last several decades due to its easy processability, biodegradability and biocompatibility (Finkenstadt et al., 2007; Rasal, Janorkar, \& Hirt, 2010; Spinella et al., 2015). However, the application of PLA is limited because of its brittleness caused by fast physical ageing, limited thermal stability and slow rate of crystallization (Zhou et al., 2013).

Cellulose nanocrystal $(\mathrm{CNC})$, one of the most promising reinforcements for nanocomposites, has attracted considerable attention because it is easily available, relatively cheap, nontoxic, has nanoscale dimensions, impressive mechanical properties, low density, and it is also biodegradable and biocompatible (D Klemm, Heublein, Fink, \& Bohn, 2005; Dieter Klemm et al., 2011; Moon, Martini, Nairn, Simonsen, \& Youngblood, 2011; Silverio et al., 2013). The typical size of the crystal ranges from 5 to $15 \mathrm{~nm}$ in width and from 100 to $500 \mathrm{~nm}$ in length (Azizi Samir, Alloin, \& Dufresne, 2005; Lima \& Borsali, 2004). Recently, Kontturi and coworkers (Kontturi et al., 2016) reported an effective approach using hydrogen chloride vapor to prepare CNC. Nanocrystals produced by the hydrogen chloride vapor approach do not have electrostatic charge, and the yield of the process can reach $90 \%$. Currently, two major techniques are used for the preparation of CNCs nanocomposites. The first technique is solvent casting through the evaporation of water or an organic solvent. Huang and 
coworkers (Lin, Huang, CHANG, Peter, et al., 2012) prepared PLA/acetylated CNC composites by solvent casting. The tensile strength of the composites decreased significantly above $6 \%$ acetylated $\mathrm{CNC}$ filler content, because of bad dispersion. The second approach is melt mixing, in which the matrix is extruded in the presence of the desired amount of freeze-dried cellulose nanoparticles. Goffin and coworkers (AnneLise et al., 2011) grafted PLA chains onto the surface of CNC and added the modified CNC to PLA to obtain composites by the melt mixing approach. Although both modified CNCs were readily incorporated into PLA through these two techniques, their reinforcing effect was compromised by the decreased interactions caused by the smaller number of $\mathrm{H}$ bonds resulting from modification.

As reported in our previous publications (Li et al., 2018; Y. Zhang et al., 2018; Yunchong Zhang et al., 2017), we have developed an approach using the Pickering emulsion approach for the preparation of PLA composites reinforced with nanocellulose crystals. A Pickering emulsion stabilized with nanocellulose may result in a more homogeneous dispersion of the nanocellulose in the final material than achieved by other techniques. In this communication, we present the use of the Pickering emulsion approach for the preparation of PLA/CNC composites. The first step is the preparation of a Pickering emulsion stabilized by CNC. The second step is the formation of PLA/CNC composite microspheres by the removal of $\mathrm{CH}_{2} \mathrm{Cl}_{2}$ and water. The last step is the preparation of the PLA/CNC composites by compression molding of plates from the microspheres. CNCs derived by the hydrogen chloride vapor 
approach were shown to stabilize efficiently oil-in-water emulsions. The homogeneity of the PLA/CNC composites and their properties were characterized by rheological, thermal and mechanical measurements.

\section{Experimental}

\subsection{Materials}

PLA (2003D, D-lactic acid: 1.4\%, L-lactic acid: 98.6\%, density: $1.24 \mathrm{~g} / \mathrm{cm}^{3}$ ) with the number-average molecular weight $\left(\mathrm{M}_{\mathrm{n}}\right)$ of $\sim 150000 \mathrm{Da}$ and weight-average $\left(\mathrm{M}_{\mathrm{w}}\right)$ of 200000 Da, respectively, was supplied by Natureworks, USA. Wood Pulp was obtained from the Xinxiang Natural Chemical Co., Ltd. The viscosity-average degree of polymerization measured in a solution of cupric ethylene diamine hydroxide (CUEN) was estimated to be 870 . The measurement was done using an Ubbelohde viscometer. Dichloromethane $\left(\mathrm{CH}_{2} \mathrm{Cl}_{2}\right)$ and $37 \mathrm{wt} \%$ hydrochloric acid $(\mathrm{HCl})$ was supplied by Sinopharm Chemical Reagent CO., Ltd.

\subsection{Preparation of CNC by the hydrogen chloride vapor approach}

The CNC was prepared by the method previously reported by Kontturi et al (Kontturi et al., 2016). The hydrolysis was carried out in a vacuum desiccator with $35 \%$ $\mathrm{HCl}$ solution poured onto the bottom. The desiccator valve was left open for more than 
a day in order to substitute the air inside the vessel by the $\mathrm{HCl}$ atmosphere completely. Subsequently, a wood pulp board was placed inside the desiccator and the hydrolysis was allowed to proceed for $8 \mathrm{~h}$ at $40^{\circ} \mathrm{C}$, after which the hydrolyzed pulp was transferred into water to rinse away excess $\mathrm{HCl}$. The hydrolyzed pulp was sonicated for 30 minutes followed by high-pressure homogenization at 800 bar for six times. The product was re-dispersed by ultrasonication for $10 \mathrm{~min}$. The concentration of cellulose was determined gravimetrically to be $1.01 \% \mathrm{w} / \mathrm{v}$ in the final dispersion.

\subsection{Preparation of PLA/CNC composites}

A CNC dispersion was diluted with deionized water to obtain cellulose dispersions with the concentrations of $0.25,0.5$ and $0.75 \mathrm{w} / \mathrm{v} \%$. The CNC to PLA ratio $(5,10$ and $15 \mathrm{wt} \%$ ) was adjusted to obtain the desired solid contents of $\mathrm{CNC}$ in the composites. A $\mathrm{CH}_{2} \mathrm{Cl}_{2}$ solution of PLA $(10 \mathrm{ml}, 100 \mathrm{mg} / \mathrm{ml})$ was added to the aqueous dispersion of CNC. The $\mathrm{CH}_{2} \mathrm{Cl}_{2}$ /water emulsion stabilized by $\mathrm{CNC}$ was formed by homogenization (IKA T18 homogenizer, Germany) at 12,000 rpm for 3 min followed by ultrasonication (Scientz JY 92-IIDN, China) for $3 \mathrm{~min} . \mathrm{CH}_{2} \mathrm{Cl}_{2}$ was evaporated at ambient temperature over 24 hours. The precipitates were vacuum filtered using a filter screen (500 mesh). The paste collected on the filter was vacuum dried at $60{ }^{\circ} \mathrm{C}$ for $24 \mathrm{~h}$. The PLA/CNC composites were produced by the compression molding of the dried paste using a Carver Laboratory Press (Carver Inc., USA) at $180^{\circ} \mathrm{C}$ and $1500 \mathrm{~kg}$ for $5 \mathrm{~min}$. 


\subsection{Characterization}

\subsubsection{Microscopy}

The morphology of $\mathrm{CNC}$ was characterized using transmission electron microscopy (TEM, JEM-2100, Jeol, Japan) operated at $100 \mathrm{kV}$ voltage. TEM micrographs were recorded on a dried droplet of the aqueous suspension containing $0.05 \%$ of CNC using a carbon-coated grid (200 mesh).

After filtration, PLA/CNC composite microspheres were studied with scanning electron microscopy (SEM, TM-1000, Hitchi, Japan) at $2 \mathrm{kV}$ and 6-8 A. The samples were kept overnight in a vacuum oven at $40{ }^{\circ} \mathrm{C}$ and then coated with a gold-palladium alloy for $40 \mathrm{~s}$.

The emulsion obtained was observed using an optical microscope (Eclipse E100, Nikon, Japan).

\subsubsection{Rheology}

The rheological characteristics of neat PLA and the PLA/CNC composites were measured using a ThermoHaake-Mars 60 rheometer with parallel plate geometry (25 mm diameter) at $200{ }^{\circ} \mathrm{C}$. A frequency sweep from $0.01 \mathrm{~Hz}$ to $10 \mathrm{~Hz}$ was carried out to study the storage modulus $\left(G^{\prime}\right)$ and complex viscosity $\left(\eta^{*}\right)$ of the composites at the constant deformation of $1 \%$. 


\subsubsection{Thermal analysis}

Neat PLA and the PLA/CNC composites were analyzed using differential scanning calorimetry (DSC, 214, Netzsch, Germany). The samples were heated from 25 to $200{ }^{\circ} \mathrm{C}$, held at $200{ }^{\circ} \mathrm{C}$ for 5 min to eliminate thermal history, cooled to $25^{\circ} \mathrm{C}$, and heated again to $200^{\circ} \mathrm{C}$ under nitrogen purge. The heating rate was $10^{\circ} \mathrm{C} / \mathrm{min}$, while the cooling rate $2{ }^{\circ} \mathrm{C} / \mathrm{min}$. Crystallization temperature $\left(\mathrm{T}_{\mathrm{c}}\right)$ and crystallization enthalpy $\left(\triangle \mathrm{H}_{\mathrm{c}}\right)$ were determined from the cooling scan. The glass transition temperature $\left(\mathrm{T}_{\mathrm{g}}\right)$, cold crystallization temperature $\left(\mathrm{T}_{\mathrm{cc}}\right)$, melting temperature $\left(\mathrm{T}_{\mathrm{m}}\right)$, cold crystallization enthalpy $\left(\triangle \mathrm{H}_{\mathrm{cc}}\right)$ and melting enthalpy $\left(\triangle \mathrm{H}_{\mathrm{m}}\right)$ were determined from the second heating scan.

The thermal decomposition of neat PLA and the PLA/CNC composites were evaluated by thermogravimetric analysis (TG, Netzsch 209F3, Germany). The samples were heated from 30 to $600{ }^{\circ} \mathrm{C}$ under nitrogen purge. The heating rate was $10{ }^{\circ} \mathrm{C} / \mathrm{min}$.

Dynamic mechanical analysis (DMA) was performed in single cantilever mode using a TA Instruments Q800 analyzer (New Castle, DE). The dimensions of the test samples were $35 \times 10 \times 0.5 \mathrm{~mm}$ (length $\times$ width $\times$ thickness). The measurements were done at constant frequency $(1 \mathrm{~Hz})$ and amplitude $(15 \mu \mathrm{m})$ in the temperature range from 30 to $120^{\circ} \mathrm{C}$ with the heating rate of $3{ }^{\circ} \mathrm{C} / \mathrm{min}$.

\subsubsection{Mechanical testing}

The tensile properties of neat PLA and the PLA/CNC composites were determined 
using a universal testing machine (UH6502, Youhong, China). The experiments were done at a gauge length of $30 \mathrm{~mm}$ and a crosshead speed of $10 \mathrm{~mm} / \mathrm{min}$. Five specimens were measured for each set of samples. The samples were thin rectangular plates with the dimensions of $100 \times 20 \times 0.5 \mathrm{~mm}$.

Flexural testing was conducted using a universal testing machine (UH6502, Youhong, China) on rectangular specimens $\left(50.8 \times 12.7 \times 0.5 \mathrm{~mm}^{3}\right)$ at a support span of $25.4 \mathrm{~mm}$ and a crosshead speed of $5 \mathrm{~mm} / \mathrm{min}$ according to the ASTM D 790-2007 standard.

\section{Results and Discussion}

\subsection{Preparation and characterization of $\mathrm{CNC}$}

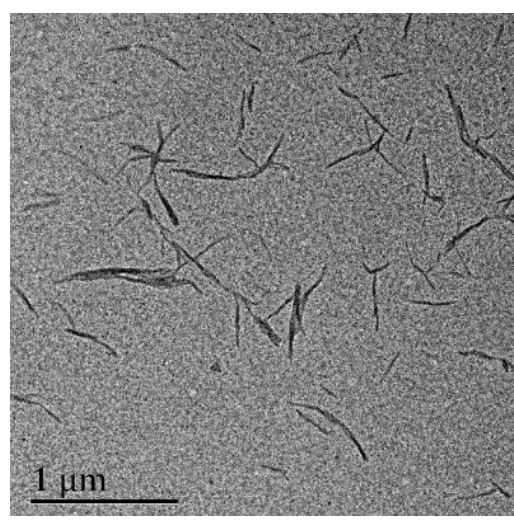

Fig. 1 TEM image of CNC prepared by the hydrogen chloride vapor approach

CNC was prepared by the hydrogen chloride vapor approach. Fig. 1 shows the TEM image of CNC obtained in the procedure. The particles are typically rigid rodshaped monocrystalline cellulose domains with about $15 \mathrm{~nm}$ in diameter and $360 \mathrm{~nm}$ in length. This result is consistent with previous work (Lorenz, Sattler, Reza, Bismarck, \& Kontturi, 2017). 


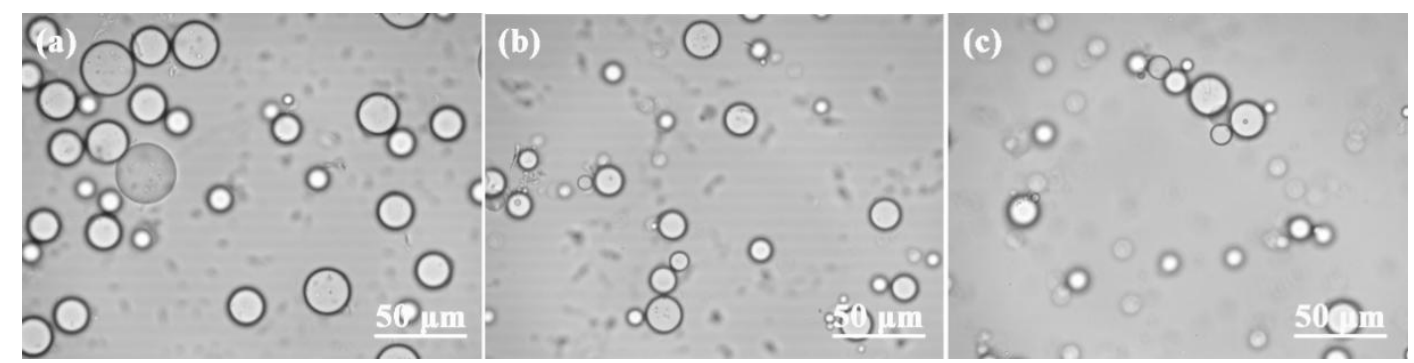

Fig. 2 Images of Pickering emulsions stabilized by 5\% (a), 10\% (b) and 15\% CNC (c).

The first step in the preparation of the PLA/CNC composites is the forming of an emulsion. The optical images of Pickering emulsions stabilized by different CNC contents are shown in Fig. 2. The diameter of the oil droplets was under $50 \mu \mathrm{m}$ for all emulsions. The results indicated that a Pickering emulsion could be successfully prepared by using $\mathrm{CNC}$ as emulsifier.

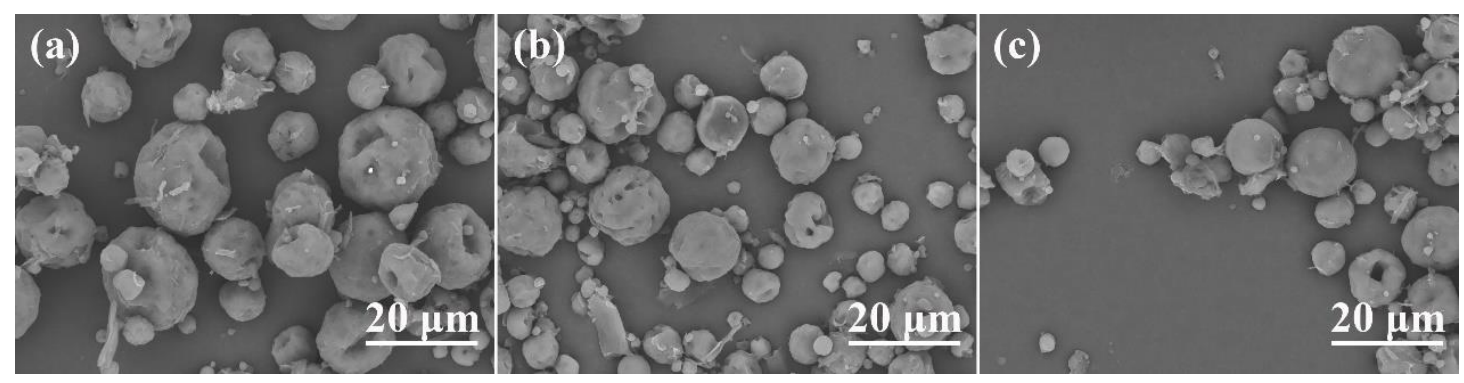

Fig. 3 SEM images of PLA/CNC composites with (a) 5\%, (b) 10\% and (c) 15\% CNC after filtration.

SEM images recorded on PLA/CNC composite microspheres with different CNC contents are presented in Fig. 3. As is shown in Fig. 3, precipitation resulted in PLA microspheres after filtration. After compression molding at $180{ }^{\circ} \mathrm{C}$, the PLA 
microspheres reinforced with CNC melted to form the composites.

\subsection{Rheological characteristics}
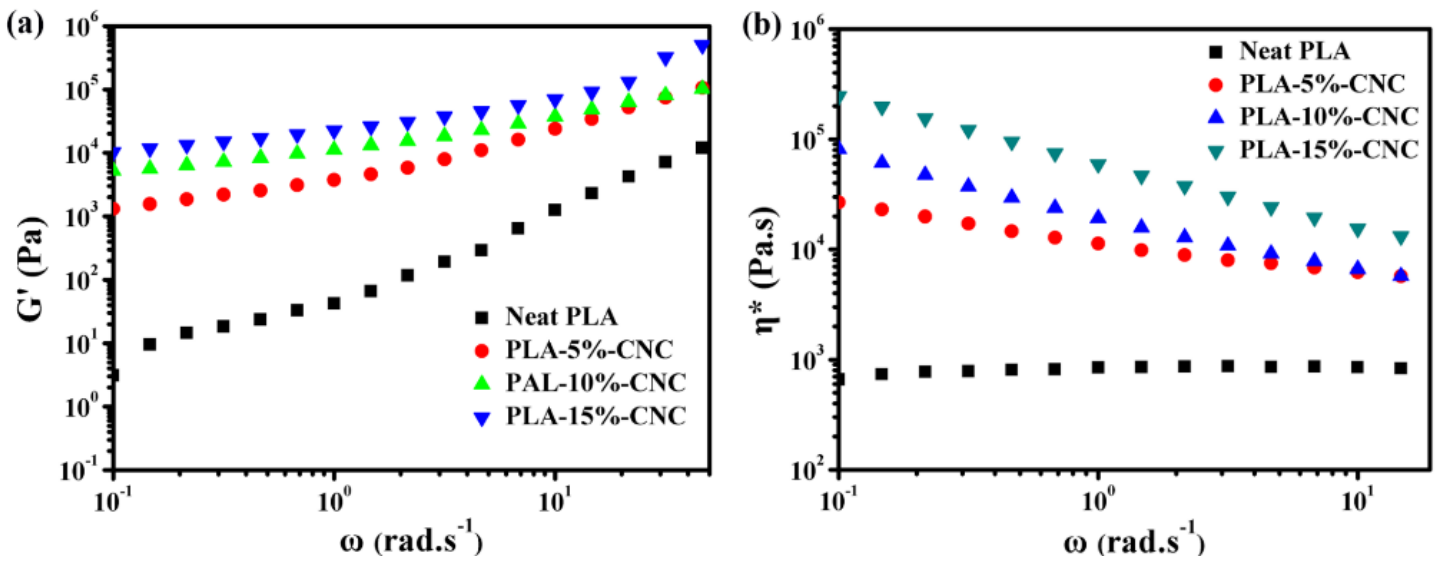

Fig. 4 Values for (a) storage modulus and (b) complex viscosity of neat PLA and the PLA/CNC

composites.

Fig. 4 presents the storage modulus $\left(G^{\prime}\right)$ and complex viscosity $\left(\eta^{*}\right)$ of neat PLA and that of the PLA/CNC composites as a function of frequency $(\omega)$ as determined in the rheological measurements. All samples exhibited stable rheological characteristics. As shown in Fig. 4a, the frequency dependence of storage modulus of neat PLA is typical for polymer melts. On the other hand, storage modulus increased and approached a plateau at low frequencies for the CNC composites. As shown in Fig. 4b, the complex viscosity of neat PLA displayed a long plateau, with a very slight shearthinning behavior at high frequencies. However, all composites exhibited an obvious shear-thinning behavior without any plateau region at low frequencies. These results indicated that $\mathrm{CNC}$ may form a network in the PLA matrix thus promoting the transition from a fluid to a solid-like behavior at high temperatures as a result of the good 
dispersion of the CNC in the PLA matrix (Bagheriasl, Carreau, Riedl, Dubois, \& Hamad, 2016; Kamal \& Khoshkava, 2015).

\subsection{Melting and crystallization}
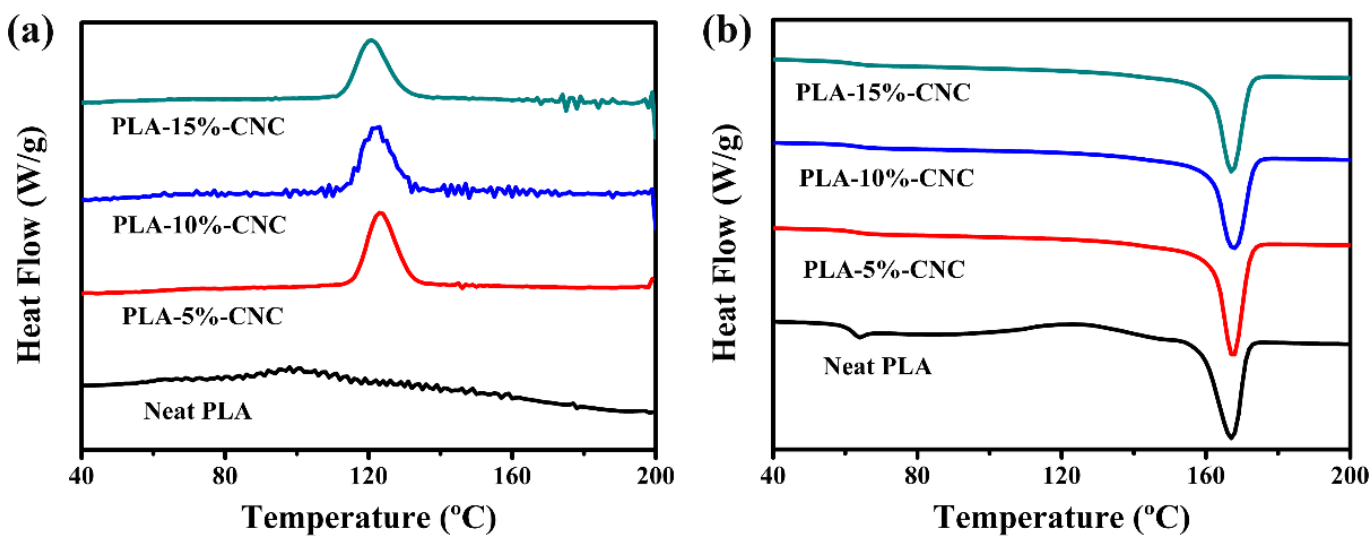

Fig. 5 DSC traces during (a) cooling and (b) second heating scan of neat PLA and PLA/CNC

composites.

The crystallization and melting behavior of PLA/CNC composites with various CNC contents were followed by DSC measurements. Fig. 5 shows the DSC traces of neat PLA and the PLA/CNC composites. As shown in Fig. 5a, the exothermic crystallization of neat PLA appears as a broad peak with low intensity indicating the slow crystallization of the polymer (Saeidlou, Huneault, Li, \& Park, 2012). As the CNC was added into the composites, the crystallization peak shifted to higher temperature and became more intense for the PLA/CNC composites as compared to neat PLA. CNC may act as nucleating agent (Fortunati et al., 2012), but this assumption is contradicted by the fact that the increase in crystallization temperature does not depend on the amount of $\mathrm{CNC}$ in the composite. The presence of CNC might also increase the 
mobility of PLA chains as shown by previous research (Müller, Imre, Bere, Móczó, \& Pukánszky, 2015).

In Fig. 5b DSC heating traces are shown which were recorded on the PLA/CNC composites and on neat PLA. The traces show the glass transition of the polymer, followed by the cold crystallization and then the melting of the polymer. Crystallization is incomplete for the neat PLA during the cooling of the sample, because of the limited mobility of the molecules (Suryanegara, Nakagaito, \& Yano, 2010). The cold crystallization peak disappears completely in the PLA/CNC composites and the melting peak becomes more intense upon the addition of CNC compared to neat PLA. All the changes indicate the increased rate of crystallization due to the presence of the cellulose nanocrystals (Suryanegara, Nakagaito, \& Yano, 2009).

The crystallinity of the neat PLA and the composites were calculated from the second heating scan according to Eq. (1) and the results are summarized in Table 1. The crystallinity of the polymer increased with increasing concentration of CNC in the PLA matrix. Compared to neat PLA, the crystallinity of the PLA-15\%-CNC composite increased considerably, by more than $100 \%$. This result confirms previous observations related to the effect of $\mathrm{CNC}$ on the crystallization of PLA. According these results CNC could may act as nucleating agent or increase the rate of crystallization of the PLA matrix by improving the mobility of the polymer chains. 


\section{Table 1}

Thermal characteristics of neat PLA and PLA/CNC composites derived from the second DSC heating scan.

\begin{tabular}{ccccccc}
\hline Sample & $\mathbf{T}_{\mathbf{g}}\left({ }^{\circ} \mathbf{C}\right)$ & $\mathbf{T}_{\mathbf{c c}}\left({ }^{\circ} \mathbf{C}\right)$ & $\mathbf{T}_{\mathbf{m}}\left({ }^{\circ} \mathbf{C}\right)$ & $\Delta \mathbf{H}_{\mathbf{c c}}(\mathbf{J} / \mathbf{g})$ & $\Delta \mathbf{H}_{\mathbf{m}}(\mathbf{J} / \mathbf{g})$ & $\chi(\mathbf{\%})$ \\
\hline Neat PLA & 60.1 & 122.2 & 167.0 & 15.8 & 36.2 & 21.9 \\
PLA-5\%-CNC & - & - & 167.5 & - & 37.5 & 42.3 \\
PLA-10\%-CNC & - & - & 167.9 & - & 36.9 & 43.6 \\
PLA-15\%-CNC & - & - & 167.1 & - & 35.8 & 44.3 \\
\hline
\end{tabular}

\subsection{Thermal decomposition, stability}

(a)

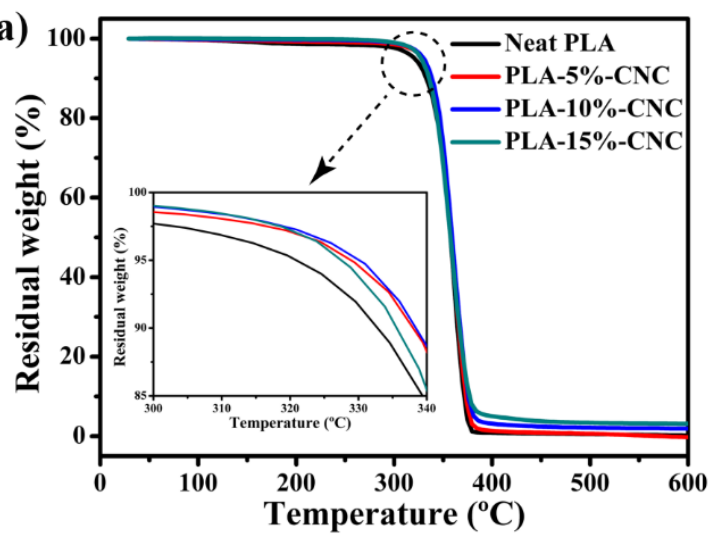

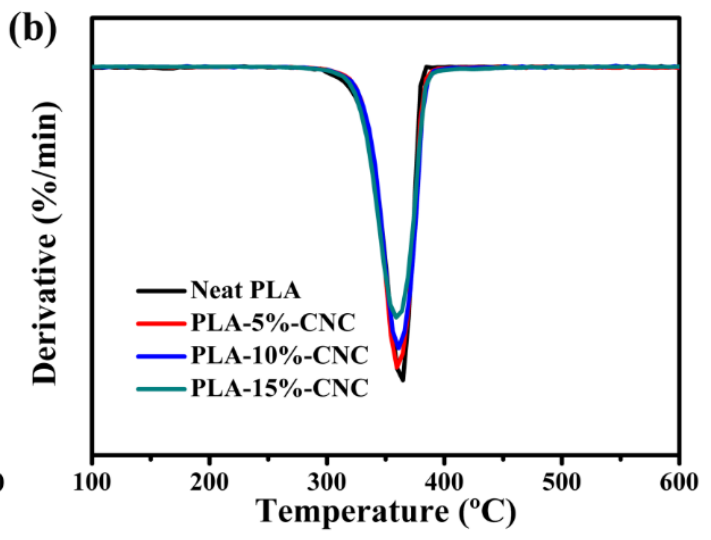

Fig. 6 TGA (a) and DTG (b) traces of neat PLA and PLA/CNC composites.

The thermal decomposition of PLA/CNC composites was determined by thermogravimetric analysis (TGA) in nitrogen atmosphere. The temperature corresponding to $5 \%$ weight loss is defined as the onset of thermal decomposition $\left(\mathrm{T}_{05 \%}\right)$. The TGA and the derivative TGA traces (DTG) are presented in Fig. 6. Compared to the neat PLA, the $\mathrm{T}_{05 \%}$ of the composites shifted towards higher temperature. The $\mathrm{T}_{05 \%}$ temperature of neat PLA was about $321^{\circ} \mathrm{C}$ and it increased to 
$330^{\circ} \mathrm{C}$ for the PLA- $10 \%$-CNC composite indicating that the addition of $\mathrm{CNC}$ improved the thermal stability of the PLA/CNC composites. The increased thermal decomposition temperature of PLA/CNC composites can be attributed to char formation during the pyrolysis of $\mathrm{CNC}$ in the composites. The forming char acts as protective barrier that suppresses the thermal decomposition of the PLA matrix (Perinović, Andričić, \& Erceg, 2010). In addition, the amount of residues increased with increasing the concentration of CNC in the PLA matrix. This result may indicate that $\mathrm{CNC}$ promotes char formation indeed. The temperature belonging to the maximum rate of decomposition $\left(\mathrm{T}_{\max }\right)$ can be also determined from the DTG traces. The comparison of $\mathrm{T}_{\max }$ for the neat PLA and the composites indicates that this characteristic temperature does not change upon the addition of CNC.

\subsection{Dynamic mechanical analysis}
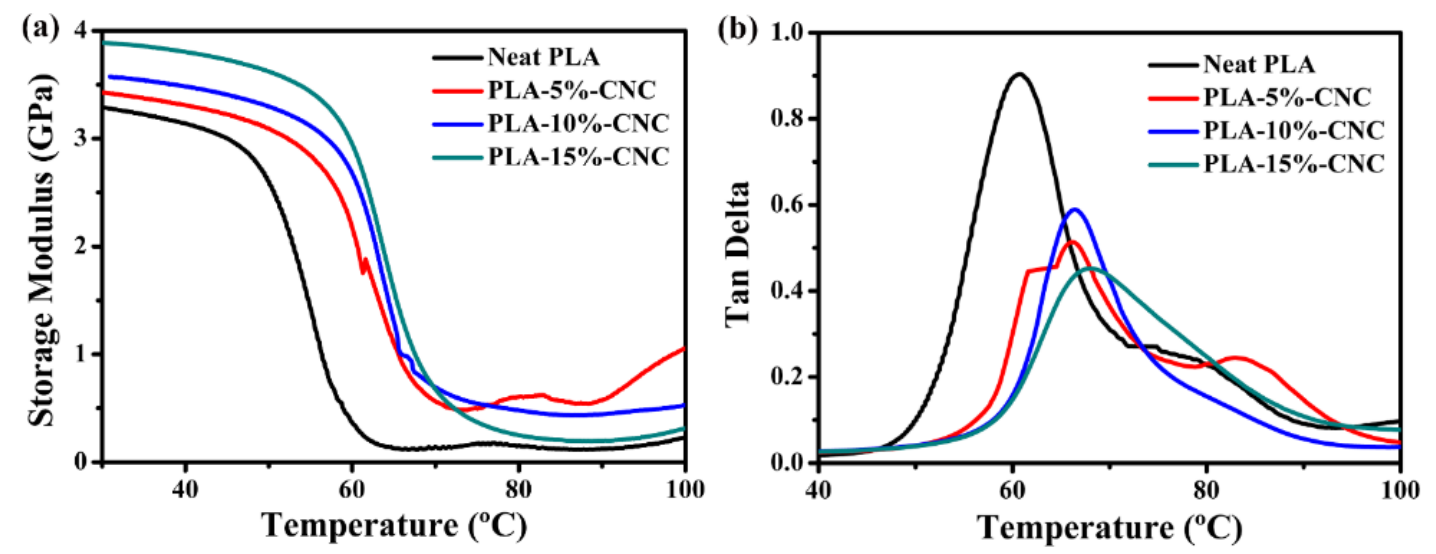

Fig. 7 Effect of CNC content (wt $\%$ ) on temperature dependence of (a) storage modulus and (b)

loss tangent. 
The thermomechanical properties of PLA/CNC composites and neat PLA were investigated by DMA to obtain information about the dynamic mechanical behavior of the composites with changing temperature. The storage modulus and the loss tangent of PLA/CNC composites and neat PLA are presented in Fig. 7. The addition of CNC to the PLA matrix increased storage modulus considerably in the entire temperature range of the experiment indicating that $\mathrm{CNC}$ acts as efficient reinforcement in the polymer. In the glassy state, the storage modulus of the composites increases with increasing CNC content as a result of the reinforcing effect of CNC in the PLA matrix. Modulus decreases during the transition from the glassy state the rubbery state above $\mathrm{T}_{\mathrm{g}}$ at around $60{ }^{\circ} \mathrm{C}$, a considerable drop in storage modulus is observed for both the neat PLA and the PLA/CNC composites. Compared to the neat PLA, a substantial increase of storage modulus from $0.14 \mathrm{GPa}$ to $0.67 \mathrm{GPa}$ was observed for the PLA- $15 \%$-CNC composite at $70{ }^{\circ} \mathrm{C}$ due to the high crystallinity of the composites and the probable network formation of CNC in the PLA matrix (Jonoobi, Harun, Mathew, \& Oksman, 2010). Cold crystallization resulted in an increase in modulus studied above $90{ }^{\circ} \mathrm{C}$ (Lin, Huang, Chang, Feng, \& Yu, 2012) for all the materials.

Fig. $7 \mathrm{~b}$ shows the changes in the position and intensity of the loss tangent peak as a function of temperature for the PLA/CNC composites and the neat PLA. The temperature of the peak may be assigned to the glass transition temperature $\left(\mathrm{T}_{\mathrm{g}}\right)$ of the polymer. Compared to neat PLA, the position of the peak shifted to higher temperatures in the composites. The $\mathrm{T}_{\mathrm{g}}$ of neat PLA was $60.8^{\circ} \mathrm{C}$, which increased to $68.1{ }^{\circ} \mathrm{C}$ for the 
PLA-15\%-CNC composite indicating that CNC hinders the movement of chain segments in the PLA matrix (Tomé et al., 2011). However, this explanation contradicts the conclusion drawn from the melting and crystallization study showing increased molecular mobility in the presence of CNC. A more probable explanation is increased crystallinity, which decreases the intensity of the loss tangent peak and shits it towards higher temperature. The decreased intensity indicates that fewer polymer chains participate in the transition as a consequence of the smaller relative amount of amorphous PLA phase, on the one hand, and due to the hindered mobility of these chains attached to the larger number of PLA crystals, on the other (Tingaut, Zimmermann, \& Lopezsuevos, 2010).

\subsection{Mechanical properties}
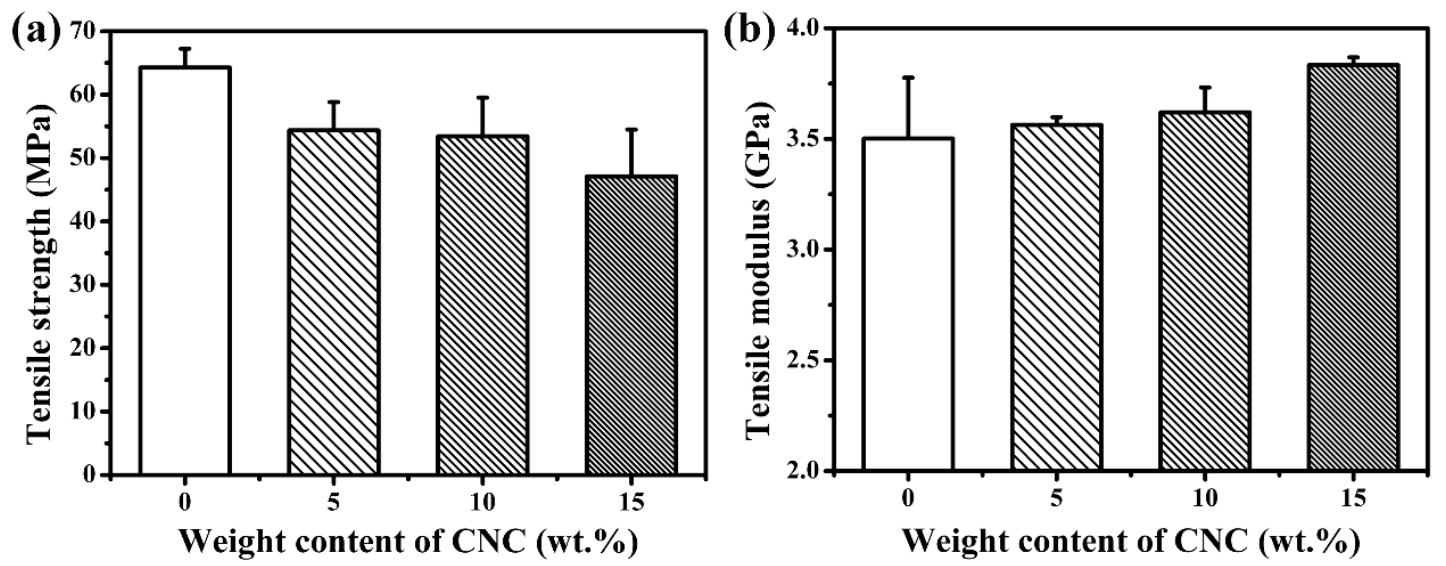

Fig. 8 Values for (a) tensile strength and (b) modulus of neat PLA and PLA/CNC composites.

The tensile properties of neat PLA the PLA/CNC composites with different CNC contents are shown in Fig. 8. The tensile strength of the composites decreases with increasing the CNC content in the PLA matrix. A slight decrease of the tensile strength 
can be observed from 64 to $55 \mathrm{MPa}$ when adding 5\% CNC into the PLA matrix. The behavior of the composites is similar to that published in the literature (Robles, Urruzola, Labidi, \& Serrano, 2015). Although the interaction between the PLA matrix (Petersson \& Oksman, 2006) and cellulose is quite strong (Faludi et al., 2014), the large stiffness of the matrix leads to the apparent decrease of strength. The real influence of $\mathrm{CNC}$ on mechanical properties and its load bearing capacity cannot be judged from the composition dependence of strength directly, it must be evaluated by model calculations. Fig. $8 \mathrm{~b}$ shows that the tensile modulus of the composites increases with increasing $\mathrm{CNC}$ content because of the good dispersion of CNC in the PLA matrix. Compared to neat PLA, an increase of the tensile modulus from 3.5 to 3.8 GPa was observed for the PLA15\%-CNC composite. Similar improvement in tensile modulus was reported earlier (Jonoobi et al., 2010; Sung, Chang, \& Han, 2017). The increase in modulus results from the reinforcing effect of the filler and from the increased crystallinity of the composites (Haafiz et al., 2013; Siqueira, Bras, \& Dufresne, 2008).
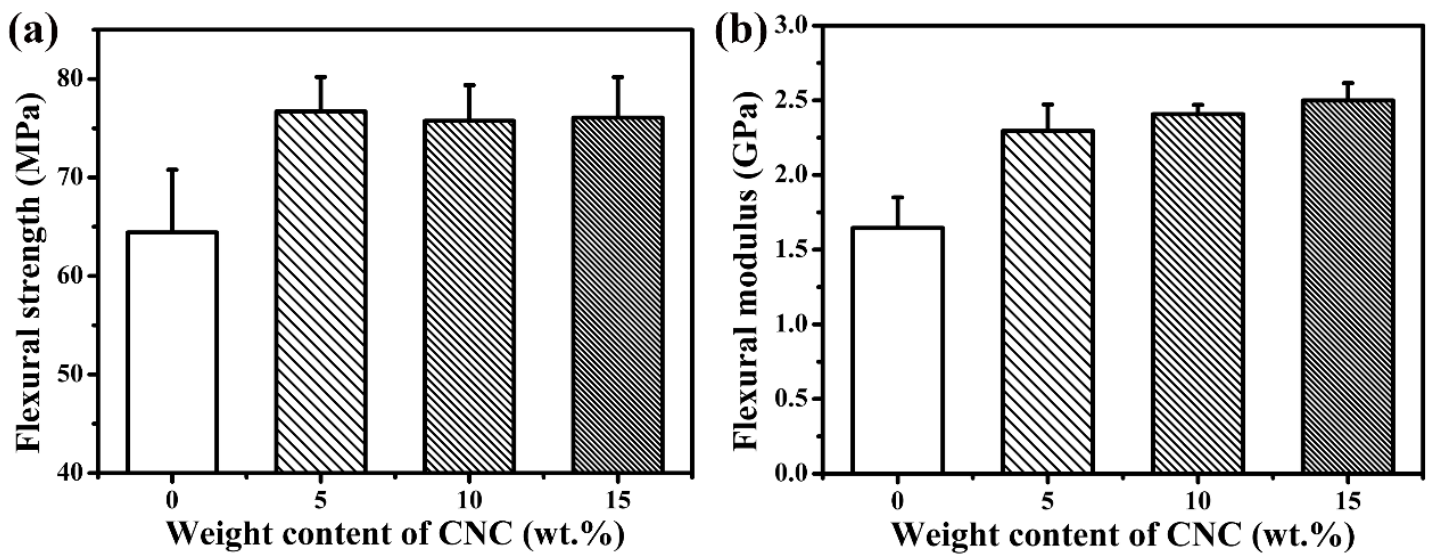

Fig. 9 Composition dependence of the (a) flexural strength and (b) modulus of PLA/CNC composites. 
The flexural properties of neat PLA and the composites are shown in Fig. 9. Compared to neat PLA, the flexural strength of the composite increased from 64 to 76 $\mathrm{MPa}$ after adding 5\% CNC to the PLA matrix. Interestingly, flexural strength does not change with increasing $\mathrm{CNC}$ content probably because of the conflicting effect of filler content and the association of the nanocrystals. According to Fig. 9b, the flexural modulus of the composites increases with increasing CNC content, similarly to results obtained in tensile testing. The modulus was improved from 1.65 to $2.50 \mathrm{GPa}$ at the CNC content of $15 \%$ compared to neat PLA. The increase of the crystallinity of the composites, the high aspect ratio of $\mathrm{CNC}$ and maybe also network formation all contributed to the improvement of flexural modulus (Dasan, Bhat, \& Ahmad, 2017).

\section{Conclusions}

PLA/CNC composites were prepared successfully by the Pickering emulsion approach. The rheological measurements indicated that $\mathrm{CNC}$ may form a network in the PLA matrix resulting in a transition from fluid to solid-like behavior at high temperatures resulting from the good dispersion of the CNC in the PLA matrix. DSC analysis confirmed that cellulose nanocrystals produced by hydrogen chloride vapor treatment increase the mobility of PLA chains and thus promote the crystallization of the polymer. The results of TG measurements indicated that $\mathrm{CNC}$ slightly increases the thermal decomposition temperature of the PLA matrix. Compared to neat PLA, the $\mathrm{T}_{05 \%}$ temperature of the composites increased from 321 to $330^{\circ} \mathrm{C}$. Compared to the neat PLA 
the composites had increased storage modulus in the entire temperature range studied. At $70{ }^{\circ} \mathrm{C}$, a substantial increase from 0.14 to $0.67 \mathrm{GPa}$ was observed in storage modulus for the PLA-15\%-CNC composite. The tensile modulus of the PLA/CNC composites increases, while their tensile strength slightly decreases as compared to neat PLA. The flexural strength and modulus improved considerably upon the addition of CNC. The results unambiguously prove that unmodified CNC produced by the hydrochloric acid vapor approach improves efficiently the thermal, mechanical and rheological properties of PLA and thus it can be a promising reinforcement for polymer composites.

\section{Acknowledgements}

Financial support from the Fundamental Research Funds for the Central Universities (2232018A3-04) of China, the National Research Fund of Hungary (OTKA K 120039) and the BME-Nanonotechnology FIKP grant of EMMI (BME FIKP-NAT). 


\section{References}

Anne-Lise, G., Jean-Marie, R., Emmanuel, D., Gilberto, S., Youssef, H., Alain, D., \& Philippe, D., 2011. From interfacial ring-opening polymerization to melt processing of cellulose nanowhisker-filled polylactide-based nanocomposites. Biomacromolecules, 12 (7), 2456-2465.

Azizi Samir, M. A., Alloin, F., \& Dufresne, A., 2005. Review of recent research into cellulosic whiskers, their properties and their application in nanocomposite field. Biomacromolecules, 6 (2), 612-626.

Bagheriasl, D., Carreau, P. J., Riedl, B., Dubois, C., \& Hamad, W. Y., 2016. Shear rheology of polylactide (PLA)-cellulose nanocrystal (CNC) nanocomposites. Cellulose, 23 (3), 1885-1897.

Dasan, Y. K., Bhat, A. H., \& Ahmad, F., 2017. Polymer blend of PLA/PHBV based bionanocomposites reinforced with nanocrystalline cellulose for potential application as packaging material. Carbohydr. Polym., 157, 1323-1332.

Faludi, G., Dora, G., Imre, B., Renner, K., Móczó, J., \& Pukánszky, B., 2014. PLA/lignocellulosic fiber composites: particle characteristics, interfacial adhesion, and failure mechanism. J. Appl. Polym. Sci., 131 (4), 39902.

Finkenstadt, V. L., Liu, C. K., Evangelista, R., Liu, L. S., Cermak, S. C., HojillaEvangelista, M., \& Willett, J. L., 2007. Poly(lactic acid) green composites using oilseed coproducts as fillers. Ind. Crops Prod., 26 (1), 36-43.

Fortunati, E., Armentano, I., Zhou, Q., Iannoni, A., Saino, E., Visai, L., . . Kenny, J. 
M., 2012. Multifunctional bionanocomposite films of poly(lactic acid), cellulose nanocrystals and silver nanoparticles. Carbohydr. Polym., 87 (2), 1596-1605.

Haafiz, M. K. M., Hassan, A., Zakaria, Z., Inuwa, I. M., Islam, M. S., \& Jawaid, M., 2013. Properties of polylactic acid composites reinforced with oil palm biomass microcrystalline cellulose. Carbohydr. Polym., 98 (1), 139-145.

Jonoobi, M., Harun, J., Mathew, A. P., \& Oksman, K., 2010. Mechanical properties of cellulose nanofiber (CNF) reinforced polylactic acid (PLA) prepared by twin screw extrusion. Compos. Sci. Technol., 70 (12), 1742-1747.

Kamal, M. R., \& Khoshkava, V., 2015. Effect of cellulose nanocrystals (CNC) on rheological and mechanical properties and crystallization behavior of PLA/CNC nanocomposites. Carbohydr. Polym., 123, 105-114.

Klemm, D., Heublein, B., Fink, H. P., \& Bohn, A., 2005. Cellulose: fascinating biopolymer and sustainable raw material. Cheminform, 44 (22), 3358-3393.

Klemm, D., Kramer, F., Moritz, S., Lindström, T., Ankerfors, M., Gray, D., \& Dorris, A., 2011. Nanocelluloses: A New Family of Nature - Based Materials. Angew. Chem., Int. Ed., 50 (24), 5438-5466.

Kontturi, E., Meriluoto, A., Penttilä, P. A., Baccile, N., Malho, J. M., Potthast, A., . . Laine, J., 2016. Degradation and Crystallization of Cellulose in Hydrogen Chloride Vapor for High-Yield Isolation of Cellulose Nanocrystals. Angew. Chem., Int. Ed., 55 (46), 14455-14458. 
Li, X., Hegyesi, N., Zhang, Y., Mao, Z., Feng, X., Wang, B., . . Sui, X., 2019. Poly (lactic acid)/Lignin Blends Prepared with the Pickering Emulsion Template Method. Eur. Polym. J., 110, 378-384.

Lima, M. M. D. S., \& Borsali, R., 2004. Rodlike Cellulose Microcrystals: Structure, Properties, and Applications. Macromol. Rapid Commun., 25 (7), 771-787.

Lin, N., Huang, J., CHANG, Peter, R., Feng, J., \& Jiahui, Y. U., 2012. Surface acetylation of cellulose nanocrystal and its reinforcing function in poly(lactic acid). Carbohydr. Polym., 83 (4), 1834-1842.

Lin, N., Huang, J., Chang, P. R., Feng, J., \& Yu, J., 2012. Surface acetylation of cellulose nanocrystal and its reinforcing function in poly(lactic acid). Carbohydr. Polym., $83(4), 1834-1842$.

Lorenz, M., Sattler, S., Reza, M., Bismarck, A., \& Kontturi, E., 2017. Cellulose nanocrystals by acid vapour: towards more effortless isolation of cellulose nanocrystals. Faraday Discuss., 202, 315-330.

Müller, P., Imre, B., Bere, J., Móczó, J., \& Pukánszky, B., 2015. Physical ageing and molecular mobility in PLA blends and composites. J. Therm. Anal. Calorim., $122(3), 1423-1433$.

Moon, R. J., Martini, A., Nairn, J., Simonsen, J., \& Youngblood, J., 2011. Cellulose nanomaterials review: structure, properties and nanocomposites. Chem. Soc. Rev., 42 (42), 3941-3994. 
Perinović, S., Andričić, B., \& Erceg, M., 2010. Thermal properties of poly( 1 lactide)/olive stone flour composites. Thermochim. Acta, 510 (1), 97-102.

Petersson, L., \& Oksman, K., 2006. Biopolymer based nanocomposites: Comparing layered silicates and microcrystalline cellulose as nanoreinforcement. Compos. Sci. Technol., 66 (13), 2187-2196.

Rasal, R. M., Janorkar, A. V., \& Hirt, D. E., 2010. Poly(lactic acid) modifications. Prog. Polym. Sci., 35 (3), 338-356.

Robles, E., Urruzola, I., Labidi, J., \& Serrano, L., 2015. Surface-modified nanocellulose as reinforcement in poly(lactic acid) to conform new composites. Ind. Crops Prod., 71, 44-53.

Saeidlou, S., Huneault, M. A., Li, H., \& Park, C. B., 2012. Poly(lactic acid) crystallization. Prog. Polym. Sci., 37 (12), 1657-1677.

Silverio, Alves, H., Neto, F., Pires, W., Pasquini, Daniel, . . . Oliveira, N., 2013. Extraction and characterization of cellulose nanocrystals from corncob;for application as reinforcing agent in nanocomposites. Ind. Crops Prod., 44(2), 427-436.

Siqueira, G., Bras, J., \& Dufresne, A., 2008. Cellulose whiskers versus microfibrils: influence of the nature of the nanoparticle and its surface functionalization on the thermal and mechanical properties of nanocomposites. Biomacromolecules, 10 (2), 425-432.

Spinella, S., Re, G. L., Liu, B., Dorgan, J., Habibi, Y., Leclère, P., . . . Gross, R. A., 
2015. Polylactide/cellulose nanocrystal nanocomposites: Efficient routes for nanofiber modification and effects of nanofiber chemistry on PLA reinforcement. Polymer, 65, 9-17.

Sung, S. H., Chang, Y., \& Han, J., 2017. Development of polylactic acid nanocomposite films reinforced with cellulose nanocrystals derived from coffee silverskin. Carbohydr. Polym., 169, 495-503.

Suryanegara, L., Nakagaito, A. N., \& Yano, H., 2009. The effect of crystallization of PLA on the thermal and mechanical properties of microfibrillated cellulosereinforced PLA composites. Compos. Sci. Technol., 69 (7), 1187-1192.

Suryanegara, L., Nakagaito, A. N., \& Yano, H., 2010. Thermo-mechanical properties of microfibrillated cellulose-reinforced partially crystallized PLA composites. Cellulose, 17 (4), 771-778.

Tingaut, P., Zimmermann, T., \& Lopezsuevos, F., 2010. Synthesis and Characterization of Bionanocomposites with Tunable Properties from Poly(lactic acid) and Acetylated Microfibrillated Cellulose. Biomacromolecules, 11 (2), 454-464.

Tomé, L. C., Pinto, R. J. B., Trovatti, E., Freire, C. S. R., Silvestre, A. J. D., Neto, C. P., \& Gandini, A., 2011. Transparent bionanocomposites with improved properties prepared from acetylated bacterial cellulose and poly(lactic acid) through a simple approach. Green Chem., 13 (2), 419-427.

Zhang, Y., Jiang, Y., Han, L., Wang, B., Xu, H., Zhong, Y., . . . Sui, X., 2018. Biodegradable regenerated cellulose-dispersed composites with improved 
properties via a pickering emulsion process. Carbohydr. Polym., 179, 86-92.

Zhang, Y., Wu, J., Wang, B., Sui, X., Zhong, Y., Zhang, L., . . . Xu, H., 2017. Cellulose nanofibril-reinforced biodegradable polymer composites obtained via a Pickering emulsion approach. Cellulose, 24 (8), 3313-3322.

Zhou, C., Shi, Q., Guo, W., Terrell, L., Qureshi, A. T., Hayes, D. J., \& Wu, Q., 2013. Electrospun Bio-Nanocomposite Scaffolds for Bone Tissue Engineering by Cellulose Nanocrystals Reinforcing Maleic Anhydride Grafted PLA. ACS Appl. Mater. Interfaces, 5 (9), 3847-3854. 